\title{
Economic Evaluation of PRIMROSE-A Trial-Based Analysis of an Early Childhood Intervention to Prevent Obesity
}

\author{
Nora Döring ${ }^{1 *}$, Niklas Zethraeus ${ }^{2}$, Per Tynelius ${ }^{1,3}$, Jeroen de Munter ${ }^{1}$, Diana Sonntag ${ }^{4,5 t}$ \\ and Finn Rasmussen ${ }^{6+}$
}

\begin{abstract}
'Prevention, Intervention and Mechanisms in Public Health, Department of Public Health Sciences, Karolinska Institutet, Stockholm, Sweden, ${ }^{2}$ Department of Learning, Informatics, Management and Ethics, Karolinska Institutet, Stockholm, Sweden, ${ }^{3}$ Centre for Epidemiology and Community Medicine, Stockholm County Council, Stockholm, Sweden, ${ }^{4}$ Medical Faculty of Heidelberg University, Mannheim Institute of Public Health, Social Prevention and Medicine (MIPH), Mannheim, Germany, ${ }^{5}$ Department of Health Science, University of York, York, United Kingdom, ${ }^{6}$ Department of Health Sciences, Lund University, Lund, Sweden
\end{abstract}

OPEN ACCESS

Edited by:

Katherine Samaras,

St Vincent's Hospital Sydney,

Australia

Reviewed by:

Sally Abell,

Monash University, Australia

Sarah Anna Lucy Price,

University of Melbourne, Australia

*Correspondence: Nora Döring

nora.doering@ki.se

tShared senior authorship.

Specialty section: This article was submitted to Obesity, a section of the journal Frontiers in Endocrinology

Received: 14 December 2017 Accepted: 02 March 2018

Published: 14 March 2018

Citation:

Döring N, Zethraeus N, Tynelius P, de Munter J, Sonntag D and Rasmussen F (2018) Economic Evaluation of PRIMROSE-A

Trial-Based Analysis of an Early Childhood Intervention to Prevent Obesity.

Front. Endocrinol. 9:104. doi: 10.3389/fendo.2018.00104
Background: Childhood obesity is a major clinical and economic health concern. Alongside the clinical understanding of obesity, there is a growing interest in designing and implementing interventions that are worth their money given the scarce resources in the health care sector. This study is one of the first efforts to provide evidence by assessing the effects and costs of a population-based primary prevention intervention targeting pre-school children attending child health centers in Sweden.

Methods: The economic evaluation is based on the PRIMROSE cluster-randomized controlled trial aiming to establish healthy eating and physical activity among pre-school children (9-48 months of age) through motivational interviewing applied by trained nurses at child health centers. The cost-effectiveness is assessed over the trial period from a societal perspective. The primary outcome was BMl at age 4. Cost data was prospectively collected alongside the trial. Scenario analyses were carried out to identify uncertainty.

Results: The estimated additional mean total costs of the PRIMROSE intervention were 342 Euro (95\% Cl: 334; 348) per child. During pre-school years direct costs mainly consist of training costs and costs for the additional time used by nurses to implement the intervention compared to usual care. Early indirect costs mainly consist of parents' absence from work due to their participation in the intervention. The incremental cost-effectiveness ratio in the base case analysis was 3,109 Euro per $1 \mathrm{BMI}$ unit prevented.

Conclusion: We cannot provide evidence that the PRIMROSE intervention is cost-effective, given the uncertainty in the effect measure. Until further evidence is provided, we recommend resources to be spent elsewhere within the field of obesity prevention. Furthermore, to achieve valid and reliable cost-effectiveness results, the economic evaluation of obesity prevention programs in early childhood should incorporate the life time impact to capture all relevant costs and benefits.

Keywords: economic evaluation, childhood, obesity, prevention, RCT 


\section{INTRODUCTION}

Despite signs of stabilization $(1,2)$, the burden of childhood overweight is still considerable in many westernized countries. Severe health concerns for the individual (3), but also significant societal and economic consequences $(4,5)$ have raised awareness among policy makers and researchers likewise to address childhood obesity through primary prevention strategies already at early ages. Still, the evidence base around the prevention of childhood obesity is far from conclusive (6-10). Nevertheless, primary health care providers and (pre-) school settings may be encouraged to address and implement behavioral counseling and other interventions as long as they do not cause harm. Yet, given the scarce resources of most health care systems, decision makers need to prioritize and shed light on opportunity costs. So far, little is known about the costs of universal population-based primary childhood obesity prevention interventions, especially in the European settings (11). Health economic evaluations are often neglected when designing and conducting intervention studies. The lack of relevant, individual, and prospectively collected data hamper the meaningful conduction of cost-effectiveness analyses. In a recent systematic review, only six studies addressing the cost-effectiveness of obesity prevention programs in early childhood were identified, and only three of them were based on a randomized trial (11) This paper aims to critically assess the costs and evaluate the economic benefits of a populationbased primary prevention intervention embedded in regular child health services targeting first time parents and their children.

\section{MATERIALS AND METHODS}

\section{Study Design and Setting}

This paper describes an economic evaluation of the PRIMROSE cluster-randomized primary prevention trial, where the costs and outcomes of the intervention were compared with those of usual care from a societal perspective. A societal perspective implies that costs also outside the health care system were included in addition to direct health care costs, i.e., productivity losses, due to participation in the trial. The present economic evaluation is an analysis of the costs and health effects of the PRIMROSE trial during the intervention period only, i.e., up to age 4 .

\section{The PRIMROSE Cluster-Randomized Controlled Trial}

The PRIMROSE trial evaluated the effectiveness of an early childhood obesity intervention delivered in the first 4 years of life, embedded in regular child health services in Sweden. Details of the study design and the intervention components have been reported previously $(12,13)$. In brief, the study included 1,355 families with 1,369 infants. The intervention took place at child health care centers $(\mathrm{CHCs})$, which were randomized into interventions $(n=31)$ and control units $(n=28)$. The intervention consisted of nine sessions in a time frame of approximately 39 months delivered by specially trained nurses. The intervention aimed to assist first time parents in promoting healthy food and physical activity habits in their children and in changing their own health behaviors if needed through the application of motivational interviewing (MI). The intervention was targeting eating pattern (i.e., regular meals together with the family, no force feeding/eating), food choices (i.e., consumption of fruit and vegetables, reduced consumption of soft drinks and snacks), and physical activity (i.e., incorporating physical activity in the everyday routine, reducing sedentary time). The intervention components were mainly targeted at the parents to become role models for their children and to increase parental self-efficacy for behavioral change. Prior to intervention, nurses attended a 5-day workshop, including an introduction to healthy nutrition, physical activity, learning theory, and social cognitive theory (SCT), as well as training in MI. During the course of the intervention, nurses received extensive and tailored feedback on their MI performance (14). Ethical approval (2006/525-31/2) was obtained from the Regionala Etikprövningsnämnden Stockholm (The Ethical Review Board Stockholm). All parents of the participating children gave informed written consent.

\section{Comparator}

Families in the control CHCs were only offered the regular age-related health check-ups of Swedish child health services, which focused on physical development and immunizations and less attention is paid to children's health behavior (15). Swedish CHCs are free or charge and attended by nearly all families in Sweden.

\section{Measurement of Clinical Outcomes}

Children's weight, height, and waist circumferences were objectively measured by study nurses at each visit to the CHC. The primary outcome was BMI at age four, applying the IOTF references for defining cut-offs (16). Secondary outcomes were mother's objectively measured anthropometrics as well as children's and mother's physical activity and food habits (13). For the current analysis, only the primary outcome, i.e., BMI at age 4, was considered.

\section{Measurement of Costs}

Costs of the intervention program included costs of a 5-day workshop offered to intervention nurses, costs of MI training, and supervision of nurses and costs of implementation. The costs of the workshop were obtained from collected invoices and salary contracts. We collected prospectively data on costs to deliver the intervention, including staff's time to deliver the intervention and parents' time to take part. This information was then supplemented with parents' average net salaries to estimate productivity losses due to participation in the intervention, based on the human capital approach. In line with current guidelines (17), we excluded the costs for research and development and any costs associated with evaluation or administration of the trial. Costs are indexed to the year 2015 and displayed in Euro using the average exchange rate from 2015 ( 1 Euro $=9.3$ SEK). 


\section{Statistical Analysis and Uncertainty Analysis}

We compared the total costs of the PRIMROSE intervention to the costs of usual care. Costs and effects were derived from participantlevel data. The incremental cost-effectiveness ratio (ICER) was expressed as cost per $1 \mathrm{BMI}$ unit prevented. The method of nonparametric bootstrapping was applied using EXCEL, where 1,000 costs and outcome pairs were generated (with replacement) (18). The results were illustrated by using cost-effectiveness acceptability curves, in which the probability that the PRIMROSE intervention is cost-effective was illustrated for different theoretical willingnessto-pay (WTP) levels for prevention of $1 \mathrm{BMI}$ unit.

\section{Scenario Analysis}

We conducted two types of scenario analysis for calculating the intervention costs. First, intervention costs were calculated based on a per-protocol basis. Instead of individual uptake and duration of meetings, we assumed full uptake (seven face-to-face meetings and two telephone meetings) and the duration of meetings according to the manual specification as previously reported (13). Missing information on parents' attendance was imputed based on the observed distribution of parents' attendances during respective meetings. In a second scenario analysis, we halved the observed duration of meetings. This is to partly account for potential overlap with usual health care during the intervention meetings, but also to allow for a shorter duration of intervention meetings if implemented in the current $\mathrm{CHC}$ practices. The effect measure was kept constant.

\section{Decision-Making Beyond Cost-Effectiveness}

In addition to the quantitative assessment of the cost-effectiveness, we applied the criteria developed by the ACE-Obesity Working Group, which are intended to incorporate other, broader aspects of decision-making. The criteria included were "strength of

TABLE 1 | Summary of unit cost information, data sources, and assumptions for education and training of nurses.

\begin{tabular}{|c|c|c|c|c|}
\hline Type of cost & Description & Unit costs & Source & Assumptions \\
\hline \multicolumn{5}{|l|}{ Education } \\
\hline \multicolumn{5}{|l|}{ Personnel time } \\
\hline Nurse & 10 nurses per education, $40 \mathrm{~h}$ & 17.9 Euro/h & $\begin{array}{l}\text { Statistics Sweden, salary statistics } \\
\text { Primrose database }\end{array}$ & Average wage rate \\
\hline Nutritionist & $\begin{array}{l}\text { Food habits and physical activity training, } \\
3 \mathrm{~h}\end{array}$ & 21.5 Euro/h & $\begin{array}{l}\text { Statistics Sweden, salary statistics } \\
\text { Primrose database }\end{array}$ & Average wage rate \\
\hline Psychologist & $\begin{array}{l}\text { SCT, learning theory, and some CBT } \\
\text { training, } 3 \mathrm{~h}\end{array}$ & 23.9 Euro/h & $\begin{array}{l}\text { Statistics Sweden, salary statistics } \\
\text { Primrose database }\end{array}$ & Average wage rate \\
\hline Ml trainer (psychologist) & $28 \mathrm{~h}$ & 23.9 Euro/h & $\begin{array}{l}\text { Statistics Sweden, salary statistics } \\
\text { Primrose database }\end{array}$ & Average wage rate \\
\hline Instructor & 2 instructors, $16 \mathrm{~h}$ & 23.9 Euro/h & $\begin{array}{l}\text { Statistics Sweden, salary statistics } \\
\text { Primrose database }\end{array}$ & Average wage rate \\
\hline Supervisor (MINT) & 5 supervisors, $8 \mathrm{~h}$ & 19.9 Euro/h & $\begin{array}{l}\text { Statistics Sweden, salary statistics } \\
\text { Primrose database }\end{array}$ & Average wage rate \\
\hline Project coordinator & $40 \mathrm{~h}$ & 16.6 Euro/h & Primrose database & \\
\hline \multicolumn{5}{|l|}{ Other costs } \\
\hline Catering and materials & Includes coffee/tea, lunches, and snacks & 3,023 Euro & Primrose database & $\begin{array}{l}\text { Calculation based on invoices } \\
\text { made for one education session }\end{array}$ \\
\hline \multirow[t]{2}{*}{ Travel } & Two-way train ride & 55 Euro & Estimate & $\begin{array}{l}\text { No information on mode of } \\
\text { transportation; Average costs for } \\
\text { medium distance train ride }\end{array}$ \\
\hline & Per nurse & & & 1,441.4 Euro \\
\hline
\end{tabular}

Training

Personnel time

\begin{tabular}{|c|c|c|c|c|}
\hline Nurse & $\begin{array}{l}9 \text { occasions, } 30 \text { min feedback on the } \\
\text { telephone }\end{array}$ & 17.9 Euro/h & $\begin{array}{l}\text { Statistics Sweden, salary statistics } \\
\text { Primrose database }\end{array}$ & $\begin{array}{l}\text { Average wage rate, full } \\
\text { maintenance }\end{array}$ \\
\hline Supervisor (MINT) & $\begin{array}{l}9 \text { occasions, } 1 \text { h preparation, } 30 \text { min } \\
\text { on the telephone }\end{array}$ & 19.9 Euro/h & Statistics Sweden, salary statistics & Average wage rate \\
\hline
\end{tabular}

Other costs

\begin{tabular}{llll}
\hline Coding of Ml conversations & 6 codings & 55 Euro & Invoice \\
\hline Recording device & One recording device per nurse & 22 Euro & Invoice \\
\hline & Per nurse & & \\
& Per child & & \\
& 667.9 Euro Euro
\end{tabular}

SCT, social cognitive theory; CBT, cognitive behavioral therapy; MI, motivational interviewing; MINT, motivational interviewing network of trainers. 
evidence," "equity," "feasibility of implementation," "acceptability of stakeholders," "sustainability," and "side-effects" (19).

\section{RESULTS}

At follow-up, there were 1,148 children with data on weight and height at age 4 . Intervention and control children at follow-up were very similar with regards to demographic characteristics and baseline characteristics (12).

\section{Main Intervention Effect}

The main results of the trial have been published elsewhere (12). In brief, there was no statistical significant indication for improvement in the primary outcome measure of children's BMI at age 4 . While the intervention effect pointed in the "right" direction, the estimate was too small to reach statistical significance with respect to group differences in the children's BMI at age 4 $[\beta=-0.11,95 \%$ confidence interval $(\mathrm{CI}):-0.31$ to 0.08$]$ (12).

\section{Total Costs}

The estimated mean total costs per participant in the intervention group were 453 Euro $(\mathrm{Min}=177, \mathrm{Max}=740)$ in comparison to 111 Euro $(\operatorname{Min}=0, \operatorname{Max}=246)$ in the control group for the usual care. The mean additional costs for carrying out this interventions were 342 Euro (95\% CI: 334; 348) per participant. The main costs components of the education program were costs of the workshop, costs of
MI training and supervision, (Table $\mathbf{1}$ ) and costs of implementation of the intervention program (Table 2). The largest component of PRIMROSE costs arose from delivery of the intervention within the CHC settings. The large intervention costs variation is mainly driven by meeting uptake.

\section{Cost of Education}

In total, 67 nurses received the PRIMROSE education, which involved a 5-day workshop, including an introduction to nutrition, physical activity, learning theory, and SCT, as well as training in MI. The MI training part of the workshop consisted of 3.5 days, with $8 \mathrm{~h}$ of training per day. Seven workshops were conducted, each with an average of 10 participating nurses. The workshops were led by a senior clinical psychologist with extensive experience in leading MI workshops, and membership of the Motivational Interviewing Network of Trainers. On average, two more licensed clinical psychologists assisted as workshop instructors. On the last day, participants' supervisor's joined the workshop. In total, there were 10 supervisors, which were each responsible for on average five nurses. On average five supervisors participated per workshop (20).

\section{Costs of Further MI Training and Supervision}

After the workshop intervention, nurses were offered feedback on their MI performance at nine occasions (four training sessions before the PRIMROSE intervention and five sessions with children

TABLE 2 | Summary of unit cost information, data sources, and assumptions for intervention delivery.

\begin{tabular}{|c|c|c|c|c|}
\hline Type of cost & Description & Unit costs & Source & Assumptions \\
\hline \multicolumn{5}{|l|}{ Group meeting } \\
\hline Number of group meetings & $\begin{array}{l}\text { On average five parental } \\
\text { units per group meeting } \\
\text { with both parents being } \\
\text { present }\end{array}$ & 1 & Primrose manual & \\
\hline Length of meeting $^{\text {a }}$ & & $1 \mathrm{~h}$ and $23 \mathrm{~min}$ & Primrose database & \\
\hline Nurse & & 17.9 Euro/h & $\begin{array}{l}\text { Statistics Sweden, salary statistics Primrose } \\
\text { database }\end{array}$ & Average wage rate \\
\hline \multicolumn{5}{|l|}{ Parents ${ }^{b}$} \\
\hline Father (7.7\%) Mother (53.2\%) & & 18.5 Euro/h 14.3 Euro/h & Statistics Sweden, salary statistics, estimate & Average wage rate \\
\hline \multicolumn{5}{|l|}{ Other costs } \\
\hline Travel & Two-way ride & 5 Euro & Estimate & $\begin{array}{l}\text { Average collective } \\
\text { communication cost for } \\
\text { short distance }\end{array}$ \\
\hline \multicolumn{5}{|l|}{ Individual meeting } \\
\hline Number of individual meetings & & 6 & Primrose manual & \\
\hline Length of meeting ${ }^{a}$ & & $53 \mathrm{~min}$ & Primrose database & \\
\hline Nurse & & 17.9 Euro/h & $\begin{array}{l}\text { Statistics Sweden, salary statistics Primrose } \\
\text { database }\end{array}$ & Average wage rate \\
\hline \multicolumn{5}{|l|}{ Parents ${ }^{b}$} \\
\hline Father (7.8\%) Mother (54.1\%) & & 18.5 Euro/h 14.3 Euro/h & Statistics Sweden, salary statistics, estimate & Average wage rate \\
\hline \multicolumn{5}{|l|}{ Telephone meeting } \\
\hline Number of telephone meetings & & 2 & Primrose manual & \\
\hline Length of meeting ${ }^{a}$ & & $22 \min$ & Primrose database & \\
\hline Nurse & & 17.9 Euro/h & $\begin{array}{l}\text { Statistics Sweden, salary statistics Primrose } \\
\text { database }\end{array}$ & Average wage rate \\
\hline \multicolumn{5}{|l|}{ Parents $^{b}$} \\
\hline Father (8.9\%) Mother (77\%) & & 18.5 Euro/h 14.3 Euro/h & Statistics Sweden, salary statistics, estimate & Average wage rate \\
\hline
\end{tabular}


in the PRIMROSE intervention group). 35 of 51 nurses (69\%) completed all nine supervision sessions that were planned to last for $30 \mathrm{~min}$ and to be based on at least $20 \mathrm{~min}$ of audio-recorded session time with parents of young children. In total, six sessions (one training session and five intervention sessions) were coded for quality of MI performance by the motivational interviewing treatment integrity-code (14).

\section{Costs of Implementation}

The PRIMROSE intervention consisted of one group meeting, six individual meetings and two telephone meetings. These meetings were conducted as add-on of the usual care provided at the CHC. In Table 2, the mean duration of visits is reported. On average, $54 \%$ of all $\mathrm{CHC}$ visits were done by mothers only. If both parents were present, the meetings were on average 15 min longer. To calculate the costs of implementation, we used individual trial data concerning uptake of meetings, parental presence, and duration of meetings.
In the RCT, the point estimate of the ICER was 3,109 Euro per 1 BMI unit prevented. The bootstrapped estimates of incremental costs and incremental benefits (represented by BMI units prevented) of the PRIMROSE interventions are presented in the cost-effectiveness plane (Figure 1). About 11\% of the bootstrapped pairs were dominated, meaning the PRIMROSE intervention costs more for less effect. Yet, the vast majority of the bootstrapped ICER estimates indicate increased benefits and greater costs.

Regarding the scenario analyses, the per-protocol analysis resulted only in marginal differences in intervention costs with a corresponding ICER of 3,553 Euro per BMI unit. When we assumed the meeting time to be halved, the ICER was reduced to 2,128 Euro per BMI unit. The cost-effectiveness acceptability curve presents the probability of cost-effectiveness of the PRIMROSE intervention given different levels of WTP per avoidance of $1 \mathrm{BMI}$ unit for all three scenarios (Figure 2). It shows that by halving the meeting times the probability of cost-effectiveness can be increased by approximately $20 \%$. With increasing WTP, one can

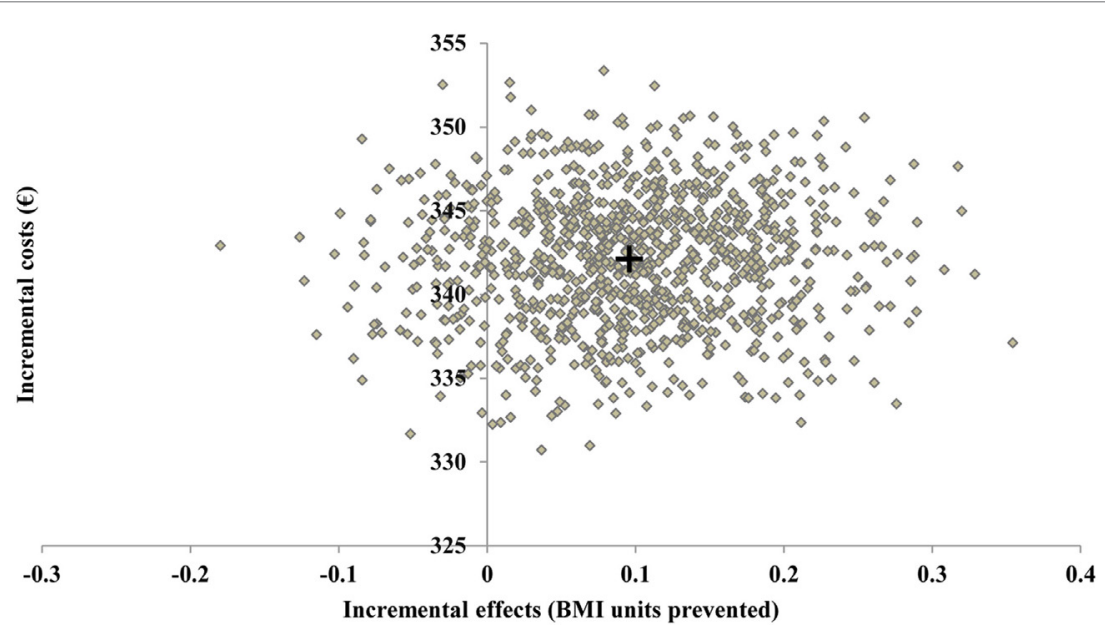

FIGURE 1 | Incremental costs and incremental effects of the PRIMROSE intervention on the cost-effectiveness plane. Results of 1,000 Monte Carlo simulations. $+=$ point estimate.

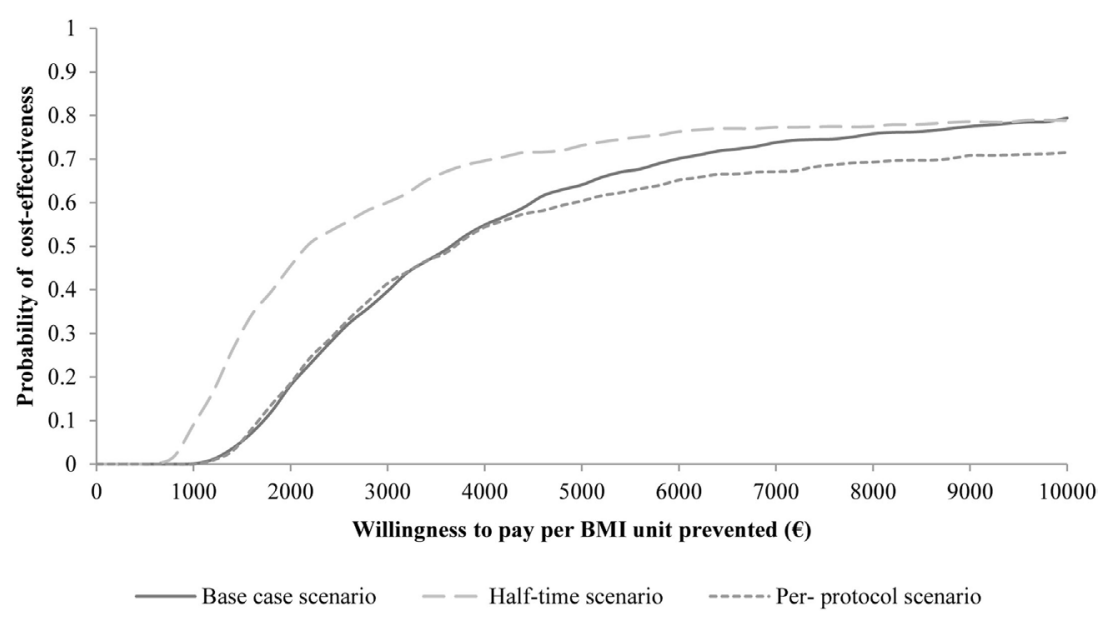

FIGURE 2 | Cost-effectiveness acceptability curves of PRIMROSE for three scenarios "Base case scenario," "Half-time Scenario," and "Per-protocol Scenario." 
TABLE 3 | Criteria for decision-making.

\begin{tabular}{|c|c|c|c|c|c|}
\hline Strength of Evidence & Equity & Acceptability & Feasibility & Sustainability & Side-effects \\
\hline $\begin{aligned} \text { - } & \text { Large cluster-RCT } \\
\text { - } & \text { Results not } \\
& \text { statistically significant }\end{aligned}$ & $\begin{array}{l}\text { - } \text { PRIMROSE population } \\
\text { has higher SES } \\
\text { compared to the } \\
\text { general population } \\
\text { - } \quad \text { Targeted to Swedish } \\
\text { speaking families only }\end{array}$ & $\begin{array}{ll}\text { - } & \text { Positively received by } \\
\text { nurses in the trial } \\
\text { - } & \text { No stigmatization } \\
& \text { (primary prevention) } \\
- & \text { On-top of regular child } \\
& \text { care }\end{array}$ & $\begin{array}{l}\text { - Embedded in regular } \\
\text { child health services } \\
\text { - } \text { Potential problems } \\
\text { concerning additional } \\
\text { time required }\end{array}$ & $\begin{array}{l}\text { - } \text { On-going training of } \\
\text { nurses during the } \\
\text { intervention, high } \\
\text { quality manual } \\
\text { - } \text { Possible issues: } \\
\text { updating of manual, } \\
\text { ensuring an adequate } \\
\text { workforce of trained } \\
\text { nurses, motivational } \\
\text { interviewing } \\
\text { competence }\end{array}$ & 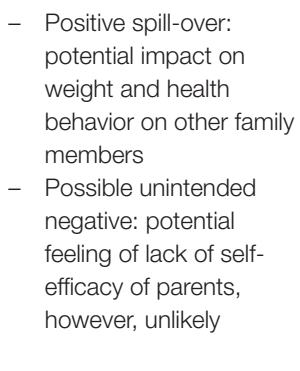 \\
\hline Major concerns & Minor concerns & No concerns & Some concerns & Some concerns & No concerns \\
\hline
\end{tabular}

observe an approximation of probabilities of cost-effectiveness for all three scenarios.

\section{Decision-Making Beyond Cost- Effectiveness}

When looking beyond the cost-effectiveness, key concerns relevant for decision-making were around the strength of evidence, feasibility, and sustainability (Table 3 ). While the intervention effect pointed in the right direction, the group difference was not statistically significant. The evidence was limited and additional, possible larger, RCTs might be needed to confirm the results. Furthermore, more research is needed to reflect on the clinical relevance of small effects on BMI during early childhood. The additional time needed by health professionals cannot be disregarded and need to be carefully evaluated. In addition, there are some issues that require resolutions to ensure sustainability, including, among others, the need of ongoing training and supervision of nurses. When implemented in practice, it can be assumed that equity issues can be neglected given that nearly $100 \%$ of the Sweden living population attends the regular $\mathrm{CHC}$ meetings, irrespective of ethnicity or SES (21).

\section{DISCUSSION}

This is the first European trial-based economic evaluation of an early childhood obesity prevention intervention. While the intervention effect pointed in the favorable direction, there was no statistical significant BMI difference at age 4 between intervention and control groups. From a societal perspective, the incremental costs of the intervention were estimated to 342 Euro per participating family over 4 years. The corresponding ICER was 3,109 Euro per BMI unit prevented. As discussed elsewhere (12), the reasons for the non-significant effect size can be manifold and do not necessarily reflect an ineffective intervention. However, given the uncertainty combined with considerable opportunity costs, the current trial-based economic evaluation of PRIMROSE suggest that resources might be better used elsewhere within the field of obesity prevention.

The PRIMROSE intervention study and its economic evaluation has a number of strengths, including the large number of participants in the RCT and the prospective planning of the economic evaluation, which allowed the inclusion of detailed individual cost data. Combined with detailed measurements of individual participation time and national statistics on age adjusted mean salary information, we were able to also include individual productivity losses. However, we need to acknowledge that we had no accurate information on the individual employment situation (i.e., unemployment or parental leave), and, therefore, cannot exclude the possibility that parental productivity losses might be under- or overestimated. Given that societal costs often outweigh the direct health care costs, we recommend for future economic evaluation of RCTs a prospective and detailed collection of all relevant economic information. Furthermore, we did not have access to individual health care utilization data during the trial period, in addition to the healthcare provided by the CHCs. One may, however, assume that the vast amount of obesity related health care costs (and savings by prevention) occurs later in life, which was confirmed in the study of Hayes et al. showing only marginal differences in health care costs up to age 2 (22). However, over the subsequent 3 years, total health care costs of children with obesity were 1.62 (95\% CI 1.12-2.36) times higher than among children with normal weight, which was driven by the higher risk of hospitalization (23). When comparing only children who were hospitalized, the differences were non-significant between the BMI groups. Therefore, more research on health care utilization during the early childhood is needed to also capture the possible short-term benefits of obesity prevention.

We are aware of only two other studies that conducted an economic evaluation that was restricted to the costs and effects during trial period for that age group $(22,24)$. The Australian trialbased economic evaluation of "Healthy Beginnings" reported an ICER of AUD 4,230 ( $\approx 2,950$ Euro) per BMI unit prevented (22). Their intervention was conducted only over a period of 2 years, yet with a similar intensity of 8 home visits, in comparison to 7 meetings and 2 telephone meetings in the PRIMROSE intervention. The economic evaluation of the live, eat, and play (LEAP) intervention showed intervention costs close to AUD 5,000 borne by both the health care sector and the families (24). However, they also included costs borne by the family by changing the diet or physical activity habits. When excluding those, the costs over the 15 months trial period AUD 973, still more costly than 
PRIMROSE. The LEAP economic evaluation did not report any ICER, given their insignificant observed effect size. This is a similar case as in the PRIMROSE intervention, yet we followed the approach suggested by Drummond who argues for the importance of conducting economic evaluations even if the effect size does not reach statistical significance (17). This approach is also followed by Moodie et al. in their economic evaluation of the "Be active eat well intervention," who calculated an ICER of AUD 547 ( $\approx 381$ Euro) per BMI unit prevented during the trial period (25). Yet, the costs and effects were aggregated to the school level in a somewhat older population, which may hinder the direct comparison to our results.

Despite similar results to other studies, the judgment of whether such an intervention is cost-effective depends on the WTP of decision makers. Currently, there is no national or international threshold on WTP for the prevention of a BMI gain in childhood. Given the challenges of calculating QALYs for this age group $(11,26)$, we hope that our calculated ICER, similar to the one calculated by Hayes et al. (22) can serve as comparator for future economic evaluations, especially in the European setting. Next to the choice of outcome measure for economic evaluations during early childhood, the preferred choice of time horizon is also debatable. There are arguments to restrict economic evaluation of early childhood obesity prevention to the observation period. These include the lack of evidence on effect maintenance, the lack of evidence on the independent association of childhood obesity and adult onset of diseases, and the methodological challenges of linking childhood obesity to utility values. Furthermore, decision makers may also be interested in the immediate costs (or savings) of an intervention. At the same time, these calculations are likely to be very conservative and important costs and health parameters are missing that allow meaningful decision on resource allocation. To truly capture the cost-effectiveness of an intervention all consequences need to be considered. For preventive obesity intervention studies during early childhood this includes health consequences and societal costs over the entire life time. A model-based simulation study is a way of synthesizing the best available data on health effect and costs in the long-run also including consequences beyond the clinical trial period. In future economic evaluations of strategies for preventing obesity in early childhood, we recommend to combine clinical trial data with data from outside the trial using a modeling framework, taking into account the consequences on costs and benefits in the long-run.

\section{CONCLUSION}

The economic evaluation of the PRIMROSE intervention demonstrated that even small intervention effects would be value for

\section{REFERENCES}

1. Rokholm B, Baker JL, Sørensen TIA. The levelling off of the obesity epidemic since the year 1999 - a review of evidence and perspectives. Obes Rev (2010) 11(12):835-46. doi:10.1111/j.1467-789X.2010.00810.x

2. Sundblom E, Petzold M, Rasmussen F, Callmer E, Lissner L. Childhood overweight and obesity prevalences levelling off in Stockholm but socioeconomic differences persist. Int J Obes (2008) 32(10):1525-30. doi:10.1038/ ijo.2008.104 money under current modeling assumptions. However, given the uncertainty around the effect measure, resources might be better used elsewhere within the field of obesity prevention, until further evidence on effectiveness is provided. In addition, more research in the phases of design, implementation, evaluation, and maintenance of early childhood interventions for obesity is needed to provide policymakers and decision makers with the information they seek to allocate scarce resources in a more efficient and sustainable way. Furthermore, to achieve valid and reliable cost-effectiveness results, the economic evaluation of obesity prevention programs in early childhood should incorporate the life time impact to capture all relevant costs and benefits.

\section{ETHICS STATEMENT}

The trial was approved by the Ethical Review Board in Stockholm, Sweden and was recorded in the ISRCTN registry (ISRCTN16991919). All subjects gave written informed consent in accordance with the Declaration of Helsinki.

\section{AUTHOR CONTRIBUTIONS}

ND substantially contributed to the design of the study, carried out the analysis, and drafted the initial manuscript. DS substantially contributed to the design of the study and the analysis, and provided substantial and critical feedback on the manuscript. JM and PT provided substantial feedback on the manuscript. NZ supported the data analysis and provided substantial feedback on the final manuscript. FR is the PI of the PRIMROSE intervention and contributed to the design of this study and provided substantial feedback on the final manuscript.

\section{ACKNOWLEDGMENTS}

The DS gratefully acknowledges salary support from the Excellence Fellowship of the Olympia-Morata Habilitation Programme. Finn Rasmussen has been supported by the Swedish Research Council for Health, Working Life and Welfare (2006-0226 and 20110413), the Swedish Research Council (K2006-27X-20069-01-3 and K2012-69X-22058-01-3), the Research and Development Committee, Stockholm County Council (2006-0324), the Regional Research Council of the Uppsala and Örebro Health Care Region (RFR-12404), Uppsala County Council, Sörmland County Council, the Public Health Committee of Stockholm County Council (0803-377), the Vardal Foundation (B2007-006), AFA Insurance (H-06:05/070001), and the Foundation of the Swedish Diabetes Society (TMA2006-004). This work has been presented, in part, as oral presentation at the European Public Health Conference (Vienna, 2016).

3. Llewellyn A, Simmonds M, Owen CG, Woolacott N. Childhood obesity as a predictor of morbidity in adulthood: a systematic review and meta-analysis. Obes Rev (2016) 17(1):56-67. doi:10.1111/obr.12316

4. Trasande L, Elbel B. The economic burden placed on healthcare systems by childhood obesity. Expert Rev Pharmacoecon Outcomes Res (2012) 12(1):39-45. doi:10.1586/erp.11.93

5. Sonntag D, Ali S, Lehnert T, Konnopka A, Riedel-Heller S, König HH. Estimating the lifetime cost of childhood obesity in Germany: results of a Markov model. Pediatr Obes (2015) 10(6):416-22. doi:10.1111/ijpo.278 
6. Blake-Lamb TL, Locks LM, Perkins ME, Woo Baidal JA, Cheng ER, Taveras EM. Interventions for childhood obesity in the first 1,000 days a systematic review. Am JPrev Med (2016) 50(6):780-9. doi:10.1016/j.amepre.2015. 11.010

7. Seburg EM, Olson-Bullis BA, Bredeson DM, Hayes MG, Sherwood NE. A review of primary care-based childhood obesity prevention and treatment interventions. Curr Obes Rep (2015) 4(2):157-73. doi:10.1007/s13679-015-0160-0

8. Wang Y, Cai L, Wu Y, Wilson RF, Weston C, Fawole O, et al. What childhood obesity prevention programmes work? A systematic review and meta-analysis. Obes Rev (2015) 16(7):547-65. doi:10.1111/obr.12277

9. Waters E, de Silva-Sanigorski A, Burford BJ, Brown T, Campbell KJ, Gao Y, et al. Interventions for preventing obesity in children. Cochrane Database Syst Rev (2011) (12):CD001871. doi:10.1002/14651858.CD001871.pub3

10. Yavuz HM, van Ijzendoorn MH, Mesman J, van der Veek S. Interventions aimed at reducing obesity in early childhood: a meta-analysis of programs that involve parents. JChild Psychol Psychiatry (2015) 56(6):677-92. doi:10.1111/jcpp. 12330

11. Döring N, Mayer S, Rasmussen F, Sonntag D. Economic evaluation of obesity prevention in early childhood: methods, limitations and recommendations. Int J Environ Res Public Health (2016) 13(9):911. doi:10.3390/ijerph13090911

12. Döring N, Ghaderi A, Bohman B, Heitmann BL, Larsson C, Berglind D, et al. Motivational interviewing to prevent childhood obesity: a cluster RCT. Pediatrics (2016) 137:e20153104. doi:10.1542/peds.2015-3104

13. Döring N, Hansson LM, Andersson ES, Bohman B, Westin M, Magnusson M, et al. Primary prevention of childhood obesity through counselling sessions at Swedish child health centres: design, methods and baseline sample characteristics of the PRIMROSE cluster-randomised trial. BMC Public Health (2014) 14:335. doi:10.1186/1471-2458-14-335

14. Bohman B, Forsberg L, Ghaderi A, Rasmussen F. An evaluation of training in motivational interviewing for nurses in child health services. Behav Cogn Psychother (2013) 41(3):329-43. doi:10.1017/S1352465812000331

15. Bohman B, Eriksson M, Lind M, Ghaderi A, Forsberg L, Rasmussen F. Infrequent attention to dietary and physical activity behaviours in conversations in Swedish child health services. Acta Paediatr (2013) 102(5):520-4. doi:10.1111/apa.12176

16. Cole TJ, Bellizzi MC, Flegal KM, Dietz WH. Establishing a standard definition for child overweight and obesity worldwide: international survey. $B M J(2000)$ 320(7244):1240. doi:10.1136/bmj.320.7244.1240

17. Drummond MF, Sculpher MJ, Torrance GW, O'Brien BJ, Stoddart GL. Methods for the Economic Evaluation of Health Care Programmes. Third edition. Oxford: Oxford University Press (2015).
18. Briggs A, Fenn P. Confidence intervals or surfaces? Uncertainty on the cost-effectiveness plane. Health Econ (1998) 7(8):723-40. doi:10.1002/ (SICI)1099-1050(199812)7:8<723::AID-HEC392>3.0.CO;2-O

19. Swinburn B, Gill T, Kumanyika S. Obesity prevention: a proposed framework for translating evidence into action. Obes Rev (2005) 6(1):23-33. doi:10.1111/j.1467-789X.2005.00184.x

20. Enö Persson J, Bohman B, Forsberg L, Beckman M, Tynelius P, Rasmussen F, et al. Proficiency in motivational interviewing among nurses in child health services following workshop and supervision with systematic feedback. PLoS One (2016) 11(9):e0163624. doi:10.1371/journal.pone.0163624

21. Kornfält R. Survey of the pre-school child health surveillance programme in Sweden. Acta Paediatr Suppl (2000) 89(434):2-7. doi:10.1111/j.1651-2227. 2000.tb03088.x

22. Hayes A, Lung T, Wen LM, Baur L, Rissel C, Howard K. Economic evaluation of "healthy beginnings" an early childhood intervention to prevent obesity. Obesity (Silver Spring) (2014) 22(7):1709-15. doi:10.1002/oby.20747

23. Hayes A, Chevalier A, D’Souza M, Baur L, Wen LM, Simpson J. Early childhood obesity: association with healthcare expenditure in Australia. Obesity (2016) 24(8):1752-8. doi:10.1002/oby.21544

24. Wake M, Gold L, McCallum Z, Gerner B, Waters E. Economic evaluation of a primary care trial to reduce weight gain in overweight/obese children: the LEAP trial.AmbulPediatr (2008) 8(5):336-41.doi:10.1016/j.ambp.2008.06.006

25. Moodie ML, Herbert JK, de Silva-Sanigorski AM, Mavoa HM, Keating CL, Carter RC, et al. The cost-effectiveness of a successful community-based obesity prevention program: the be active eat well program. Obesity (2013) 21(10):2072-80. doi:10.1002/oby.20472

26. Frew E. Economic evaluation of childhood obesity interventions: reflections and suggestions. Pharmacoeconomics (2016) 34(8):733-40. doi:10.1007/ s40273-016-0398-8

Conflict of Interest Statement: The authors declare that the research was conducted in the absence of any commercial or financial relationships that could be construed as a potential conflict of interest.

Copyright (C) 2018 Döring, Zethraeus, Tynelius, de Munter, Sonntag and Rasmussen. This is an open-access article distributed under the terms of the Creative Commons Attribution License (CC BY). The use, distribution or reproduction in other forums is permitted, provided the original author(s) and the copyright owner are credited and that the original publication in this journal is cited, in accordance with accepted academic practice. No use, distribution or reproduction is permitted which does not comply with these terms. 